\title{
A Study on Influencing Factors and Countermeasures in Management of Multi- campus Universities
}

\author{
Yaohua $\mathrm{Wu}^{1}$, Zhihui $\mathrm{Wu}^{2}$ \\ 1. School of Business Administration \\ 2. Guangzhou Institute of Modern Industrial Technology \\ South China University of Technology \\ Guangzhou, P. R. China \\ e-mail: yhwu@scut.edu.cn
}

\begin{abstract}
-for improving management performance of multicampus universities, the challenge of management in multicampus universities is discussed firstly. Secondly, points of view in management mode, resources integration, running costs, exchanging between teacher and student, and culture blending, the influencing factors what cause the current management situation are discussed. Finally, the measuring principles and effective management strategies are proposed, which are of benefit to coordinated development of the multicampus universities.
\end{abstract}

Keywords-multi-campus universities; higher education; management mode; countermeasures

\section{INTRODUCTION}

Since the early 1990 's, the step of management system reform in higher education is significantly more quickly than before in china, especially in the construction of new campus of colleges and universities. With the situation in the vast consolidation between universities, trend from elite education to mass education and the expanded enrollment scale, more and more multi-campus universities have been formed. Compared with the single campus university, multicampus universities are more special and more complex in terms of number of campuses, instructional scale, discipline integration and the cultural diversity among campuses. There is new challenge in countermeasure analysis and highly effective management method to multi-campus universities. There have been many works done by the academic and educational communities to research these issues recently [15]. However, the theoretical and practical innovation of educational management in the multi-campus universities are problems, which contain management model, resource allocation, running cost, culture inheritance etc. These challenge issues should be solved and defined step by step. The first step of the solution of the issues is to analyze the factors influencing the management of multi-campus universities.

How to enhance the efficiency of management? That is a critical problem for thoughts on influencing elements in the management system of multi-campus university. Since the management systems are related to the external and internal environment, organization situation, historical origins and activities of the members in the organization. The problem is generated in different management methods. Therefore, the principle for efficiency in management has to be presented. The performance of the management of multi-campus universities can be verified.

In this paper, the current problems of multi-campus universities are presented by comparing with the single campus universities. The factors analysis from the view points of management model, resources integration, running cost, exchange between teachers and students and the campus culture are discussed. The principle of the effectiveness of the management in multi-campus universities is concluded. Finally, several corresponding countermeasures are put forward, including the choice of management model, the integration of educational resources, the running cost control, the construction of campus culture and the construction of information platform.

\section{The Challenge of Management in Multi- CAMPUS UNIVERSITIES}

\section{A. the Types of Multi-campus Universities}

Formation and development of multi-campus universities suggested that those universities could be divided into the following three types.

1) The merged multi-campus universities: To expand the space, improve the strength, optimizing the resources of regional higher education, two or more independent in colleges and universities formed into a restructured university through the merger in a geographical scope, such as Peking University, Zhejiang University, Central South University, Hunan University and Changsha University of Science and Technology.

2) The expanded multi-campus universities: To solve the development bottleneck of universities, the multicampus universities are formed by establishing a new campus outside the original area. Sometimes the expand enrollment is the main factor of leading to expansion of the school, such as Shanghai Jiao Tong University and Nanjing University etc.

3) The hybrid multi-campus universities: In fact, some colleges and universities are formed both through the universities merger and new campuses building, which are 
called as the hybrid multi-campus universities. Since they have the features of merged and expanded multi-campus universities, the situation is more complex in the hybrid multi-campus universities.

\section{B. The Characteristics Compared with Single Campus Universities}

Compared with the single campus universities, the multicampus universities have the following characteristics.

- The multi-campus universities not only have at least more than two campuses, but also the campuses location is geographically dispersed.

- The discipline is more complete than before with the universities merging and expanding. The increase in the number of discipline usually means the subject coverage and the increased discipline types. The universities are also more comprehensive.

- The cultural diversity and management complexity are clear in multi-campus universities. Due to difference in tradition, disciplinary structure and management style, each merged university had formed its own campus culture. It would be significantly different from other campus.

- With the merging and expansion, the scale of multicampus universities is usually huger than single campus universities. Both the number of staff and the number of students have significant increase in multi-campus universities.

The multi-campus universities could be described as dispersed, complete, complex and large. That refers to the universities have dispersed campuses, complete discipline, complicated situation and a large-scale staff. The strategic planning, management and construction of the multi-campus universities should be determined according to the above characteristics. It is a prerequisite for achieving coordinated development in multi - campus universities.

\section{The Issue Existing in Management of Multi-campus Universities}

Since multi-campus universities appear for near 20 years in China, the management of multi-campus universities has been a new project to academic and educational. It is short time for intensive studying in theory and at practice. There are some problems during the management of multi-campus universities. Those issues are concluded as following.

- It is the supervising patterns issue, which focuses on the choice of centralization or decentralization on the management of multi-campus universities. According to the management theory, centralization mode has the advantage of unified configuring district resources from the whole university. But that could greatly increase the cost of management in the point of the principle of managing range. Each campus has bigger autonomy that would be conducive to strengthening the activity of the school. Its disadvantages is difficult to conduct a fair allocation of education resources, integration of the disciplines is also more difficult, which does not meet the original purpose of the establishment of multi-campus universities.

- Resources integration is the second question. Resources restructuring and improving the efficiency are the initial goals of the multi-campus universities. The personnel, financial, equipment, books and school space increase expansion of the scale in multi-campus universities, but the optimization goal of management is the economy of scale.

- Running cost is the third issue. During the expansion and merging period, at least a billion of investment is used in land expropriation, construction planning, design, building etc. When the universities are established, the cost of transport commuting between campuses, repeating purchasing equipment and books in each campus, organizing quality education activities, construction of communication facilities are large cash input too.

- Teacher-student communication is another problem. Many teachers are already familiar with the original campus environment. They are not willing to stay in the new campus general, let alone the placement of their family in the new campus. In some campus, the students are form with the juniors. The cultural and professional tradition of the original university cannot be passed from one generation to the next.

- The integration of campus culture is another major issue. Since the campus culture is an accompanying product, the brand of a university is culture precipitation, which is formed with the hardware such as featured building, campus environment, and facilities of teaching and scientific researching, and the software such as famous masters, studying and teaching style formed many years.

\section{INFLUENCING FACTORS IN THE MANAGEMENT OF MULTI-CAMPUS UNIVERSITIES}

From the above analysis of the issue of the management in the multi-campus universities, some of the ideas and thoughts can be put forward. What is the underlying reason causing the above problem? How to find these reasons? And then follow the principle and smooth the management among the campuses. Therefore, the influencing factors in the management of multi-campus universities are discussed as following.

\section{A. the Factors Influencing the Management Mode}

Multi-campus university is a complex organization, which has the characteristics of dispersion, whole, complex, large. Many factors have a profound influence on the exploration and innovation of management mode.

The factors of management mode are including the external environment of management, the organizational strategies, the organizational technology, campus culture, and stage of the organization, size of the organization, the subject structure and distribution of the organization, as shown in Fig.1. 


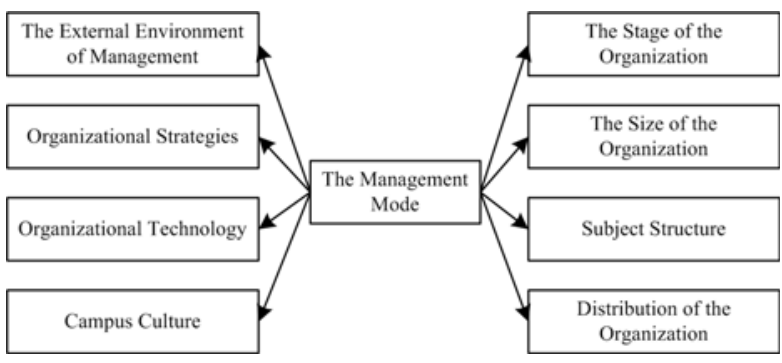

Figure 1. The major factors of the management mode

\section{B. the Factors Influencing the Resource Integration}

Education resource includes tangible and intangible resources, the two things going together, interacting, which do effects on the resource integration of multi-campus university.

- The design and placement of those tangible facilities, teaching venues, apparatus, experimental equipment, determine the distribution of intangible resources, course system, and foundation of discipline and departments.

- The intangible resource is the baton and direction of is a tangible resource. On one hand, the idea of running or the curriculum provision guide investment and input methods of the fixed assets. On the other hand, traditional cultural is the striving goal and effort direction of the staff.

\section{C. the Factors Influencing the Running Cost}

The funding requirement of a large-scale multi-campus university is a great quantity. It is often difficult to implement spending cuts. The situation of funds living beyond its means is increasingly serious. There are several main factors affect of the running cost in multi-campus university.

- The enrollment breaks the balance of the finance of higher education. As accumulating the demand has quickly been broken out in the short term, the pressure on spending beyond the financial capacity of higher education.

- Due to system problems, university has low profitability and heavy debt. State funding is the mainly source of education funding.

- Lack of preparation or lack of early warning in loan risks, lead to the psychology of conformity and obedience on the banks and the government's attitude to university loans.

- Duplicate information assessment and educational public activities among campus lead to inevitably waste. Campus unclear communication between people, information and materials also cause the increase in operating costs.

D. the Factors Influencing the Interaction between Teachers and Students

The lack of contact with each other is the main reason for estranging the students from the teachers. The communication primarily happens in the process of teaching and learning in the classroom, other than that, there is no more contact.

- There is a long tradition of respecting teacher in China, but the traditional often standardize the two sides as "order" and "obedience". Teachers are always playing the role of the dominatrix. And those students can only be passive and obedient. The two sides cannot communicate on equal status, relationship between teachers and students actually become an unequal relationship of personality.

- Inadequacy of the management system makes teaching and education has no real measure of teacher education standards. And only some of the responsible teacher or the professional teachers communicate with students initiatively.

- Nowadays student body and mind grow and change in advance. Their independence grows as well as the range of activities growing, so the links of students and teachers naturally reduce.

\section{E. the Factors Influencing Culture Blend}

The blend of cultures is an important part in the multicampus university, which is also difficult to be grasped and measured.

- The result of the formation of multi-campus university is under the forces, but the culture is the accumulation and precipitation. Its infiltration, dissemination, integration between campus cannot be done overnight.

- Almost originated everything has to be disrupted and restructured, when multi-campus university form. That not only requires time, but also needs the right skills and strategies. The establishment of specific systems and mechanisms might accompany with the process of collision and conflict.

\section{PRinciples And StRAtegies In the Management of Multi-CAMPUS UnIVERSITIES}

\section{A. Principles for Effective Management System}

The analysis of the factors could find the source of the problems in management. And then we also need to clear the standard of treatment solving the problems. So some principles are developed to evaluate the effectiveness of management strategies as following.

1) Combination of systemic and diversity: Multi-campus university is a whole system, where there are multiple subsystems. Each subsystem is responsible for different tasks. As to the management, each campus is necessary to follow the macro planning and obey the control of the entire system. On the other side, the campus should be full of energy and live its own feature.

2) Priority of operating schools: an important objective to the formation of multi-campus universities is to optimize resources for education, improve teaching effectiveness. Management of multi-campus universities must be based on 
improving education effectiveness. That is a starting point and destination for management evaluation.

3) The down-shift of management center: Implementing management center moving down in the school-campuscollege-department level. This not only helps decision makers and practitioner separation, but also let school management get free from tedious daily business, and having time to think about the school strategic issues, but also to give all colleges and departments authority on handling their own affairs.

4) Ruling by law: Multi-campus university management should establish the modern university system with its reality situation at the initial formative stage. It brings benefits for perfecting the function and power of each administration departments and colleges. It is also good at running the school under the "law".

5) Promoting informatization: Advanced network technology guarantees construction of multi-campus management information system. Interaction, randomness and invisibility of the information management system make it safe and convenient for effective management of multi-campus universities.

\section{B. Countermeasure Suggestions for Management of Multi-} campus University

According to the principle, we can make some suggestions about the countermeasure for the management of multi-campus university. The management strategies focus on the choice of management mode, the integration of educational resources, running cost control, construction of campus culture and information platform construction respectively as following.

1) The choice of management mode: To make clear the external environment and smooth out the subordinate relationship. And then draw a planning of campus function and integrating disciplines. Finally, we should make reasonable centralization of powers to enhanced vitality.

2) The integration of educational resources: The integration can be realized with the sharing of discipline resources, the sharing of curriculum resources, the sharing of experiment resources, the sharing of library books resources and the sharing of the human resources.

3) The control of running cost: Strengthening the financial management and financial analysis can bring benefit of reduction the running cost. Strengthening the management of financial budget can also enhance the management of investment. On the other way, we can raise the funds of the university from opening up more channels. We also need to train the business consciousness and strengthening cost accounting of the university.

4) The construction of campus culture: When the multicampus university formed, both cultural integration and cultural reconstruction should start together. The specific measures put forward is carried out, we should consider in tandem as whole university, while all features of campus culture are expected to retain.

5) The construction of information platform: We propose the construction of digital campus proposal. During the process of construction, Some aspect construction should be included, which is the construction of network infrastructure, network construction and its basic application system, construction of the supporting system, and the construction of information service system, etc.

\section{CONCLUSION}

Since management performance is an important issue in the multi-campus universities, and the factors influencing the effective management are the key point of management evaluation, a deep analysis about the existing issues is presented based on the formation study of the merged and expanded multi-campus universities. With the features compared with single campus universities, influencing factors are discussed, which include aspects of management mode, education resource integration, running cost control, interaction between teachers and students, and the campus culture blending. Finally, the principles of measuring management validation are presented. Some countermeasure suggestion for the management of multi-campus universities are put forward based on those principles.

\section{ACKNOWLEDGMENT}

The authors would like to acknowledge the financial support of the 2010 China Humanities and Social Research Special Task Project Foundation of the Ministry of Education (Grant No. 10JDSZ3034); Higher Education Project in Fundamental Research Foundation of China Central Universities (Grant No. 2011SJ006); Research on the Construction of Campus Culture Project Foundation, South China University of China (Grant No. x2hjN8120140).

\section{REFERENCES}

[1] Y.X. Guo, "Optimal Management of Multi-campus University: A case in Jiangxi,” Applied Mechanics and Materials, vol.55-57, Jan. 2011, pp. 1951-1956.

[2] H.M. Jin and S. M. Wang, "Exploration on management model and operating mechanism of multi-campus university in China," 2010 International conference on educational and network technology, IEEE Press, Jun. 2010, pp. 531-534, doi:10.1109/ICENT. 2010. 5532094.

[3] Y.H. Wu and Z.G. Zhang, "Research on Effectiveness of Ideological and Political Education of College Students Based on Voluntary Service Activities - A Case Study of Volunteer in Guangzhou Asian Games,” Studies in Ideological Education, vol.9, Sep. 2011, pp. 668672.

[4] Z.F. Xie, "Analysis of Multi-campus University Students Managing Work Modes,” 2nd International Conference on Information Science and Engineering, IEEE Press, Dec. 2010, pp. 97-100, doi:10.1109/ICISE. 2010. 5691129.

[5] J.C. Hua, K. Gao, J.P. Ge, "The Scale and Efficiency Relation Analysis of Multi-Campus Universities," Modern Education Management, vol.9, Sep. 2012, pp. 18-22. 